\title{
O ESPORTE E O ÍDOLO DAS ORIGENS: DESVELANDO A CONSTITUIÇÃO DO FUTSAL
}

\author{
Daniele Cristina Carqueijeiro de Medeiros \\ Universidade Estadual de Campinas, Campinas, São Paulo, Brasil.
}

\begin{abstract}
Resumo
Diversas fontes que trabalham com a história do futsal fornecem informações desencontradas e de pouca confiabilidade para os estudiosos da área. Este trabalho se vale dessas informações e procura, por meio de um debate historiográfico, problematizar a "origem" e a constituição dessa prática esportiva ao longo do tempo. O artigo objetiva, primeiramente, discutir o ídolo das origens no futsal e problematizar o surgimento desse esporte. Na segunda parte, o artigo analisa as transformações na prática desse esporte por meio de mudanças propostas pelas confederações. Conclui-se serem necessárias uma desnaturalização e uma reinterpretação da história do futsal. Este artigo procurou estabelecer novas possibilidades de se pensar a história do futsal e suas relações com a sociedade brasileira.
\end{abstract}

Palavras-chave: História. Futsal. Origem do futsal. História das confederações.

\section{THE SPORT AND THE IDOL OF ORIGINS: UNVEILING THE CONSTITUITION OF FUTSAL}

\begin{abstract}
A lot of sources about history of futsal show diverging and poorly reliable information to students and researchers of this area. This research uses these information and problematizing the "origin" and constitution of this sportive practice over time. This article aims, in the first part, discuss the idol of origins in futsal, and problematizing the appearance of this sport. In the second part, the article analyses the transformation in practice through changes proposed by confederations. In conclusion, it is necessary a denaturation and reinterpretation of history of futsal. This article aims to establish new possibilities to understand the futsal history and its relations with Brazilian society.
\end{abstract}

Keywords: History. Futsal. Origins of futsal. History of confederation.

\section{EL DEPORTE Y EL ÍDOLO DE LOS ORÍGENES: DESCUBRIENDO LA CONSTITUCIÓN DEL FÚTBOL SALA}

\begin{abstract}
Resumen
Diversas fuentes que trabajan con la historia del fútbol sala ofrecen informaciones incongruentes y poco confiables para los estudiosos del área. Este trabajo se apoya en esas informaciones y busca, a través de un debate historiográfico, problematizar el "origen" y la constitución de esa práctica a lo largo del tiempo. El artículo tiene el objetivo de, en su primera parte, discutir el ídolo de los orígenes del futbol sala y problematizar el surgimiento de ese deporte. En la segunda parte, el artículo analiza las transformaciones en la práctica de
\end{abstract}


ese deporte por intermedio de cambios propuestos por las confederaciones. Se concluye que es necesaria una desnaturalización y reinterpretación de la historia del fútbol sala. Este artículo buscó establecer nuevas posibilidades de pensar la historia del fútbol sala y sus relaciones con la sociedad brasileña.

Palabras clave: Historia. Fútbol sala. Origen del fútbol sala. Historia de las confederaciones.

\section{Introdução}

Marc Bloch (2001, p. 41) inicia seu livro Apologia da história com a seguinte indagação: "Para que serve a história?". Essa pergunta é passível de inúmeras interpretações e respostas e servirá como mote para a discussão a ser empreendida neste artigo.

Uma das respostas possíveis a essa questão é que a história é um baú de curiosidades; ela entretém, diverte, atrai. Embora tenha caminhado a passos largos como ciência, especialmente ao longo do século XX, essa interpretação dos dados históricos ainda é bastante comum em nossa época, especialmente quando se pensa na história dos esportes.

Usualmente, a história de uma determinada prática esportiva é pensada através da ideia de "marco inicial", ou seja, a partir de uma data específica em que um "inventor" realizou a primeira partida daquele esporte e fundou a prática no país. Outras vezes, as curiosidades históricas permeiam os álbuns dos torcedores aficionados, que decoram todas as informações do time ou da modalidade. Ainda, existem aqueles que atribuem à história a capacidade de permitir que se entenda a "evolução" de uma determinada prática esportiva. Afinal, a história do esporte, ou de uma modalidade específica, seria mesmo capaz de resolver todas essas questões? Ou, ainda, estaria ela apenas ligada a essas interrogações?

Ao analisar os discursos ligados às investigações da origem do futebol no Brasil, Victor Melo (2017) concluiu que a maioria das informações veiculadas a respeito desse esporte não tem relação com fontes históricas verdadeiras ou toma dos relatos uma verdade parcial como base. Além disso, as discussões realizadas a respeito dessa "origem" poucas vezes problematizam os reais significados desse discurso.

Uma breve busca na internet ${ }^{1}$ aponta três informações distintas em relação à invenção do futsal, ou como na época era chamado, o futebol de salão: uma delas toma a década de 1930 e a Associação Cristã de Moços do Uruguai como os detentores da "criação" dessa prática. Outra corrobora essa informação, mas pondera que o estabelecimento das regras foi feito no Brasil na década de 1940. Há ainda uma versão que transfere a origem para a Associação Cristã de Moços de São Paulo.

A mesma problemática estabelecida por Melo (2017) em relação ao futebol se dá também com relação ao futsal: distintas origens são mencionadas e consideradas verdadeiras, poucas informações veiculadas são ligadas às fontes históricas de fato existentes e são praticamente nulas as reflexões a respeito dessas informações. Ou seja, não há uma preocupação em se pensar quais os possíveis significados desses fatos.

Este trabalho, longe de ser conclusivo, esboça algumas interpretações a respeito do cenário de criação e estabelecimento das práticas do futebol de salão e, posteriormente, do futsal, em busca de novas compreensões históricas para os dados amplamente divulgados a respeito desse esporte. De acordo com Paul Veyne (2008, p. 86), "O conhecimento do

\footnotetext{
${ }^{1}$ As páginas consultadas nessa busca foram: WIKIPEDIA. Futebol de salão. Sem local, sem data. Disponível em: 〈https://pt.wikipedia.org/wiki/Futebol_de sal\%C3\%A3o>. Acesso em 12 abr. /2018; SUAPESQUISA. Futsal. Sem local, sem data. Disponível em: <https://www.suapesquisa.com/educacaoesportes/futsal.htm> Acesso em: 12 abr. 2018.; UNIFAE. A origem do futsal no Brasil. Sem local, sem data. Disponível em: <http://www.posunifae.com.br/noticias/398/a-origem-do-futsal-no-brasil >. Acesso em: 12 abr. 2018.
} 
passado não é um dado imediato, a história é um domínio onde não pode haver intuição, mas somente reconstrução, e onde a certeza racional dá lugar a um saber de facto cuja fonte é estranha à consciência". Assim, é preciso reinterpretar e compreender os dados para que eles façam sentido para a construção da história.

O objetivo deste artigo é discutir o futsal a partir de um debate historiográfico, que problematiza a "origem" e a constituição da prática ao longo do tempo, por meio de sua relação com as confederações. O principal intuito é estabelecer novas possibilidades de se pensar o futsal e sua história, permitindo-nos reinterpretar os dados estabelecidos a priori.

Este trabalho, embora aborde a questão da história do esporte, não trabalha com fontes específicas do tema, mas busca dialogar tanto com alguns autores da história quanto com pesquisadores da história do esporte, no sentido de compreender o estabelecimento desse esporte no Brasil e no mundo.

A primeira parte do trabalho procura problematizar a "origem" do futsal através da noção de ídolo das origens postulada pelo historiador Marc Bloch (2001). Assim, a investigação se dará em torno dos significados atrelados à "invenção" desse esporte e das implicações das diferentes versões sobre esse fato. A segunda parte do trabalho problematiza a história do futsal através das federações e confederações, partindo da noção de campo, de Pierre Bourdieu (2003). O intuito desta segunda parte é analisar como o futsal se tornou um esporte internacionalmente instituído a partir de fatos que derivaram de uma disputa de poder de federações.

\section{O ídolo das origens no futsal}

Qual a importância em saber exatamente onde ou quando surgiu determinada prática? Para Marc Bloch (2001), não basta conhecer a origem se esta vier deslocada de todos os sentidos históricos atrelados àquela prática e àquele fenômeno. Essa obsessão pelo conhecimento do marco inicial é chamada pelo autor de ídolo das origens:

Naturalmente cara a homens que fazem do passado seu principal tema de estudos de pesquisa, a explicação do mais próximo pelo mais distante dominou nossos estudos às vezes até à hipnose. Sob sua forma mais característica, esse ídolo da tribo dos historiadores tem um nome: a obsessão das origens. (BLOCH, 2001, p. 56).

Essa obsessão pelas origens em geral vem acompanhada de tentativas de legitimação dos fenômenos. No futsal, essa máxima não é diferente. Existem duas vertentes bastante populares que versam sobre o surgimento do futsal, ou, como na época se chamava, do futebol de salão. Uma delas data da década de 1930 e tem como lugar a Associação Cristã de Moços do Uruguai. De acordo com relatos evocados em Vicari (2014), Zaratim (2012) e pela própria Confederação Brasileira de Futebol de Salão, ${ }^{2}$ teria sido nesse local que as primeiras experiências do futebol dentro de uma quadra foram desempenhadas. A segunda vertente indica que a origem do futebol de salão teria se dado nas quadras da Associação Cristã de Moços de São Paulo, na década de 1940.

No entanto, não há certezas a respeito dessas versões nos trabalhos publicados sobre a história desse esporte. Tanto os pesquisadores citados acima quanto a confederação não encontraram documentação que comprovasse alguma das proposições. Vicari (2014) relata ainda que uma inundação ocorrida no Estádio do Maracanã destruiu parte dos arquivos da Confederação Brasileira de Desportos (CBD), nos quais havia documentação referente ao futebol de salão e sua origem.

2 CBFS. O esporte da bola pesada que virou uma paixão. Sem local, sem data. Disponível em: <http://www.cbfs.com.br/2015/futsal/origem/index.html >. Acesso em: 16 nov. 2017. 
Retomando as afirmações de Marc Bloch (2001, p.60), mais importante do que saber exatamente o local de origem de um fenômeno é refletir sobre as lógicas que permeiam esse fato, tendo em vista que "nunca se explica plenamente um fenômeno histórico fora do estudo de seu momento". Logo, façamos aqui alguns questionamentos: por que a prática do futebol de salão teve início entre as décadas de 1930 e 1940 ? Por que essa prática se inicia no Brasil/Uruguai, países da América do Sul? Qual a importância da legitimação da origem do futebol de salão para cada um desses países?

Primeiro, é preciso pensar que, para esses dois países, especialmente nas décadas de 1930 e 1940, criou-se uma grande rivalidade no futebol de campo. O futebol tem usos e significações bastante semelhantes nos países da América do Sul ao longo do século XX, como apontam Drumond (2008), Santos (2006) e Breitkreitz (2012). Ancorado em discursos populistas, esse esporte forneceu elementos para o desenvolvimento de regionalismos, sentimentos patrióticos e representações populares desde sua instituição, no final do século XIX.

Para além das vitórias e das derrotas em âmbito internacional, vale ressaltar que nesse período já havia uma disseminação do futebol no Brasil, o que o tornou o esporte mais popular do país. ${ }^{3}$ Giglio (2007) aponta que, já no final da década de 1920, o futebol brasileiro havia atingido boa parte da sociedade e se popularizado para além das elites, que primeiro realizavam essa prática. Ao longo do tempo, estabeleceu-se uma certa relação entre o futebol e as características da população brasileira, o que cunhou cada vez mais, ao redor do mundo, a ideia de que o Brasil era o "país do futebol". Para Daolio:

[há] similaridade e combinação de algumas características originais do futebol com determinados hábitos, atribuídos ao estilo do povo brasileiro. Explicando melhor, parece haver uma certa relação entre as exigências do esporte e as características socioculturais do povo brasileiro. (DAOLIO, 2006, p. 110).

Assim, se havia uma disputa com a equipe uruguaia pelo domínio do cenário futebolístico na América do Sul, bem como uma difusão do esporte ao longo do território brasileiro, é bastante provável que qualquer prática relacionada ao futebol também entrasse no nível dessas disputas. O futebol de salão, originário do esporte mais praticado nesses dois países, foi parte de um discurso de apropriação do futebol como prática dominante. Ou mesmo forjou os intentos desses países de se tornarem os "donos da prática", já que o primeiro, nascido na Inglaterra, não poderia oferecer a titulação a esses dois países.

Uma outra forma de interpretar o "nascimento" do futsal entre as décadas de 1930 e 1940 é relacioná-lo ao rápido crescimento das grandes cidades e à falta de espaços para a prática do futebol de campo. O crescimento do perímetro urbano e, consequentemente, de um modo de vida urbano foi um dos motes de desenvolvimento do esporte moderno (MELO, 2000; GUTMANN, 2004). A prática esportiva e seu dinamismo, sua temporalidade, sua lógica voltada à vitória relacionavam-se perfeitamente com a lógica urbana que se engendrava.

O processo de desenvolvimento urbano, especialmente em São Paulo, fez com que cada vez mais os espaços, que outrora eram públicos, se tornassem privados, especialmente por conta da especulação imobiliária. Embora até os dias atuais haja uma enormidade de campos

\footnotetext{
${ }^{3}$ Diversos pesquisadores que estudam o futebol como um fenômeno social brasileiro compreendem essa prática como um produto externo, que veio de um país "avançado", que era a Inglaterra, mas que foi facilmente apropriado e transformado no país. Essa prática foi rapidamente relacionada aos períodos de lazer da classe operária urbana brasileira e, pouco a pouco, houve uma intensa troca de significações entre a cultura brasileira e o futebol, o que permitiu inúmeras aproximações e diálogos. Dentre os sentidos forjados a esse esporte podemos citar as honras pessoais, o orgulho patriótico, entre outros (DAOLIO, 2006; GIGLIO, 2007; DAMATTA, 1982; MELO, 2000).
} 
de futebol, ${ }^{4}$ sendo inclusive o dispositivo de lazer mais presente nas cidades (MASCARENHAS, 2005), a urbanização e a frequente ocupação de espaços diminuíram a quantidade de campos disponíveis para a prática. A própria justificativa no site da Confederação Brasileira de Futebol de Salão fornece algumas pistas sobre essa relação com a urbanização: "havia uma grande dificuldade em encontrar campos de futebol livres para poderem jogar e então começaram a jogar suas 'peladas' nas quadras de basquete e hóquei" (O ESPORTE, 2017).

Há, ainda, uma outra relação existente entre o oferecimento de espaços e a prática esportiva nas primeiras décadas do século XX: o advento dos clubes esportivos. Na cidade de São Paulo, desde 1899 os clubes começaram a marcar o entorno dos rios Tietê e Pinheiros, oferecendo uma gama de práticas esportivas, como natação, remo, basquete e tênis. No Rio de Janeiro não foi diferente: a partir da segunda metade do século XIX, os clubes esportivos começaram a se estabelecer e a organizar em suas dependências uma grande quantidade de esportes (MELO, 2015a; MELO, 2015b).

A introdução dos clubes nas grandes cidades brasileiras do período mudou a relação dos habitantes com a prática esportiva e de divertimento e modificou os espaços disponíveis para essas práticas. A introdução dos jogos de quadra, trazidos especialmente pelos imigrantes por meio dos clubes esportivos, fez com que houvesse sempre uma quadra disponível para os jogos.

É possível pensar, através das discussões de Chartier (1990), que as práticas são apropriadas, ou seja, há uma nova interpretação delas quando realizadas por outras pessoas. Assim, as práticas de quadra trazidas pelos imigrantes nos clubes esportivos foram readequadas às práticas realizadas no Brasil, especialmente o futebol, que já havia se tornado, nas primeiras décadas do século XX, um esporte difundido e bastante praticado. Logo, o modelo clubístico que se disseminava disponibilizou esses espaços para a prática esportiva e permitiu o surgimento de um novo esporte.

Em suma, é possível inferirmos diversos questionamentos aos dados relativos ao surgimento do futsal. De uma afirmação rodeada de poucas exatidões, é possível levantar novos questionamentos que nos permitem pensar sobre quais as condições de existência desse esporte. Ou, como questiona Bourdieu (2003, p. 182): como foi possível o surgimento de determinados esportes, ou quais as condições históricas e sociais que fizeram com que os esportes surgissem e se estabelecessem? Ainda, para esse autor, é preciso estranhar algo que nos parece óbvio, ou seja, pensar sobre o impacto do esporte moderno na sociedade e na vida das pessoas. Assim também deve ser com a história do futsal: deve-se desnaturalizar sua existência e pensar sobre as condições sociais que permitiram seu desenvolvimento.

Após "desnaturalizar" o surgimento do futsal, podemos ainda pensar nas condições de desenvolvimento dessa prática esportiva: como foi possível que o futebol de salão, nascido na América do Sul, tenha se tornado um esporte internacional e muito praticado em alguns países europeus? Como se deu a transformação nas regras desse esporte, que passou de futebol de salão a futsal?

Essas questões, bem como a forma como as federações se apropriaram da prática desse esporte, serão discutidas no próximo item, a partir da noção de campo (BOURDIEU, 2003).

\section{As mudanças nas regras e no jogo: o impacto das federações}

Em matéria publicada na seção de esportes do site Terra, ${ }^{5}$ alguns dias antes do Campeonato Mundial de Futsal de 2012, há a apresentação de uma carta enviada pela

\footnotetext{
${ }^{4}$ Entendidos aqui não necessariamente como campos de medidas oficiais.

${ }^{5}$ TERRA. Em comunicado, CBFS confirma retirada de duas estrelas da camisa. Sem local, 5 nov./2012. Disponível em: <http://esportes.terra.com.br/futsal/mundial-de-futsal/em-comunicado-cbfs-confirma-retirada-de-
} 
Confederação Brasileira de Futebol de Salão (CBFS) sobre a polêmica ligada à retirada de duas estrelas do escudo brasileiro:

A Confederação Brasileira de Futsal (CBFS) vem a público informar que de maneira surpreendente recebeu comunicado da FIFA determinando a exclusão de duas estrelas contidas em seus uniformes alusivas às conquistas de dois certames mundiais promovidos pela Federação Internacional de Futebol de Salão (Fifusa), antes de a FIFA assumir os destinos da modalidade. (TERRA, 5 nov. 2012).

A carta publicada pela CBFS buscava relativizar a decisão da Federação Internacional de Futebol (FIFA), antes do mundial, de retirar as estrelas do escudo brasileiro relativas às conquistas mundiais promovidas pela então entidade federativa do esporte, a Federação Internacional de Futebol de Salão (FIFUSA), que coordenava o futebol de salão antes da entrada da FIFA na gerência desse esporte. A carta termina afirmando que a Confederação Brasileira, embora tivesse acatado a decisão da Federação Internacional, faria uma cruzada pela volta do escudo original, em respeito àqueles que participaram daquelas conquistas. Essa matéria jornalística associa-se à questão abordada neste item do artigo: a relação das mudanças de regras e mudanças no jogo com as federações que comandaram o esporte ao longo dos anos.

Para compreender essa relação com as alterações no jogo, a noção de campo de Bourdieu será importante. Para esse autor, todas as manifestações que envolvem o fenômeno esportivo ocupam um espaço social chamado campo, bem como outras práticas sociais existentes. No interior de cada campo existem disputas, lutas e concorrências em busca da hegemonia de algumas práticas em detrimento de outras; aquelas que se sobressaem o fazem através de seu poder simbólico. O autor define a prática esportiva como um espaço de produção dotado de uma lógica e uma história próprias, dentro do qual estão inseridos os produtos esportivos, as práticas esportivas e os consumidores. O que o autor se pergunta é: como se produz a demanda por certos produtos esportivos? Como se estabelece o gosto por alguns esportes? ${ }^{6}$

Oferecendo algumas pistas, Bourdieu (2003, p. 182) sugere que se comece a procurar essas respostas nas condições históricas e sociais que permitiram o estabelecimento de determinados esportes e, com isso, suas instituições, seus agentes, que têm como função:

[...] assegurar a representação e a defesa dos interesses dos praticantes de um esporte determinado e, ao mesmo tempo, elaborar e aplicar as normas que regem estas práticas, até os produtores e vendedores de bens (equipamentos, instrumentos, vestimentas especiais, etc.) e de serviços necessários à prática do esporte (professores, instrutores, treinadores, médicos especialistas, jornalistas esportivos, etc.) e produtores e vendedores de espetáculos esportivos e de bens associados (malhas, fotos dos campeões ou loterias esportivas, por exemplo). (BOURDIEU, 2003, p. 182).

A noção de campo esportivo ${ }^{7}$ nos leva a refletir sobre o estabelecimento do futebol de salão e, posteriormente, do futsal, como um esporte dotado de regras próprias, materiais

duas-estrelas-da-camisa,7718d4f3eb6fa310VgnCLD200000bbcceb0aRCRD.html>. Acesso em: 20 nov. 2017.

${ }^{6}$ Marchi Jr. (2001) analisa as relações existentes especificamente dentro do campo esportivo. O autor, baseandose em Bourdieu e em outros autores que compreendem o esporte através dessa perspectiva, insere o esporte e o processo de esportivização dentro de uma lógica de mercantilização que seria, segundo ele, responsável por diversas lutas simbólicas no interior desse campo.

${ }^{7}$ Valemos-nos da interpretação de Marchi Jr. (2001) a respeito da ideia de constituição de campo esportivo de Bourdieu. Ao analisar o voleibol e as mudanças de estrutura e técnicas ao longo do século XX no Brasil, o autor interpreta a ideia de campo de Bourdieu para pensar um esporte que não viera diretamente de uma transformação dos jogos populares antigos, como o futebol ou o rúgbi. O autor compreende que esse processo de transição não 
esportivos próprios, campo de jogo delimitado, federações nacionais e internacionais e, inclusive, com uma relação com o campo midiático bem estabelecida.

Em 1971, quando o futebol de salão já havia se formado como uma prática esportiva no Brasil, com suas regras, lógica interna, campo e número de jogadores, buscou-se inscrevê-lo como uma prática de alcance mundial para que os campeonatos pudessem ser disputados e as ligas e seleções nacionais fossem formadas. Assim, determinou-se, em solo brasileiro, a criação da FIFUSA, primeira entidade a reger esse esporte, suas regras e seus campeonatos no mundo. Nesse primeiro momento, a entidade contava com a filiação de países sul-americanos e de Portugal.

A partir da década de 1980, essa entidade começou a promover alguns campeonatos internacionais, como o Campeonato Pan-Americano de 1980. Dois anos depois, em 1982, foi realizado em São Paulo o primeiro Campeonato Mundial. Esse campeonato, que contou com a participação de dez países, foi vencido pelo Brasil.

A divulgação do esporte no ano de 1982 foi vasta por conta do campeonato. Uma ampla cobertura foi feita pela revista esportiva Placar $^{8}$ e havia um grande clima de euforia, pois o campeonato seria disputado apenas um mês antes da Copa do Mundo de Futebol. O Brasil, já tricampeão da Copa e consolidado como país do futebol, consagrou essa fama ao vencer o torneio de futebol de salão, compreendido também como um torneio futebolístico. As matérias de divulgação do evento apresentavam títulos bastante confiantes ("Este caneco já é nosso"; "Nessa Copa só dá Brasil"; "Esta copa é nossa"), além de demonstrarem esperança na conquista do Brasil em ambas as disputas.

Havia uma comparação constante entre o desempenho da seleção de futebol de salão e a seleção de futebol de campo. No discurso da mídia, o futebol de salão, um "subproduto" do futebol de campo, servia como um aquecimento para o clima do mundial de futebol. $\mathrm{O}$ subtítulo da matéria da revista Placar de 11/6/1982 era: "A uma semana da Copa, Brasil conquista um título mundial". Ainda, os grandes craques da seleção de salão eram constantemente comparados aos craques da seleção de campo, sendo Douglas, por exemplo, uma "espécie de Zico".

Ainda que nesse período houvesse uma federação responsável pela prática desse esporte, entende-se que ele ainda não havia se instituído como um campo esportivo. Primeiramente, pela quantidade de times inscritos, que era de apenas dez. Em segundo lugar, a relação com as regras ainda era instável. Em matéria da revista Placar, esse fato fica evidente:

Ainda existem algumas diferenças básicas na prática desse esporte de um país para outro. Na Holanda, por exemplo, o lateral é cobrado com o pé; na Itália, vale gol dentro da área, que por sinal é quadrada; em alguns países, o atleta não é substituído após cometer cinco faltas, ao contrário da regra brasileira, que também só permite cinco substituições, enquanto na Europa o revezamento é livre. (ESTA COPA..., 1982, p. 32).

Embora apenas dez países tenham participado dessa edição do Campeonato Mundial de Futebol de Salão, houve grande repercussão internacional do evento, o que fez com que a FIFA se interessasse pela modalidade. Foi a partir desse momento que esse campo esportivo se tornou motivo de disputas de poder. A FIFA, entidade máxima futebolística, passou a requerer o título de coordenadora de todos os eventos ligados ao futebol. A FIFUSA, por sua

é o único existente na formação de práticas esportivas, e que algumas modalidades, como o caso do vôlei e do futsal, foram inventadas sem a necessidade da proveniência dos jogos aristocráticos ou populares. Para o autor "[os esportes como vôlei e futsal] constituíram seus campos e sua história por conta da pertinência de sua criação com a representatividade e necessidade social existentes nas estruturas de origem" (MARCHI JR., 2001, p. 41).

${ }^{8}$ Em suas edições de 28/5, 4/6 e 11/6, todas no ano de 1982. 
vez, pretendia manter-se como detentora da organização desse esporte, que começou a se difundir internacionalmente.

Às vésperas do mundial de 1985, a FIFUSA precisou alterar o nome da modalidade, pois os domínios do futebol pertenciam à FIFA. Assim, a FIFUSA transformou seu esporte em futsal e organizou o segundo campeonato mundial na Espanha. ${ }^{9}$

A partir desse momento, travou-se um verdadeiro campo de disputas pela legitimação da verdadeira prática do futebol de salão, ou futsal. Embora a FIFUSA tenha continuado a existir e a manter entidades nacionais filiadas, a FIFA utilizou cada vez mais de seu poderio para enfraquecer a concorrente e firmar-se como a legítima detentora da prática. A configuração desse campo esportivo passou pela legitimação da prática através das federações, conforme afirmou Bourdieu (2003) a esse respeito.

Em 1989, a FIFA promoveu sua primeira Copa do Mundo de Futsal, em meio a essa desavença federativa. $\mathrm{O}$ capital simbólico ${ }^{10}$ dessa federação era muito maior do que aquele da FIFUSA, o que fez com que já em 1989 o mundial contasse com a participação de 16 países. A partir desse momento, houve uma dissidência na prática, gerando dois modos diferentes de se praticar esse esporte, com distintas regras, técnicas e táticas e, certamente, com federações diferentes responsáveis por gerenciá-las.

O campo esportivo do futsal tendeu cada vez mais a uma homogeneização dessa prática ao redor das regras estabelecidas pela FIFA, em virtude de seu maior capital simbólico. Tanto que, em 2002, a entidade foi legitimada pelo Comitê Olímpico Internacional (COI) como a única autorizada a promover torneios oficiais de futsal. Entretanto, como toda prática social é dotada de ressignificações e resistência, as práticas que outrora eram chamadas de futebol de salão não deixaram de existir, sendo associadas a um movimento de resistência à FIFA, batizado em 2002 de Associação Mundial de Futsal (AMF), que passou a organizar essas práticas ao redor do mundo.

Provavelmente, nas escolas dos países "fundadores" do futebol de salão - Brasil e Uruguai -, essa prática não seja mais ensinada, mas sim o futsal, como é organizado pela FIFA. As regras do futebol de salão, como, por exemplo, a cobrança de laterais com a mão ou a impossibilidade de se marcar gols de dentro da área adversária, são geralmente entendidas como ultrapassadas em relação à prática do futsal divulgada e organizada pela FIFA.

O historiador Georges Vigarello (2002) analisou a concepção de técnicas corporais e como elas se transformaram ao longo do tempo, recrutando novas destrezas, como velocidade, agilidade, rapidez e força. Essas características foram, pouco a pouco, adicionadas às práticas esportivas modernas e se tornaram determinantes para o sucesso ou o fracasso de um atleta em uma modalidade.

Com relação aos esportes coletivos, essas técnicas corporais também se alteraram no decorrer do tempo, especialmente com mudanças no jogo e nas regras. Marchi Jr. (2001), em estudo sobre o voleibol, relacionou essas mudanças às questões técnicas e táticas e, consequentemente, às mudanças necessárias para que o jogo se tornasse mais televisivo, como no caso da "vantagem".

\footnotetext{
${ }^{9}$ AMF. Historia de La AMF. Disponível em: <http://www.amfutsal.com.py/p/historia〉. Sem local, sem data. Acesso em: 12 abr. 2018 .

10 "O simbólico, para Bourdieu, é por excelência uma manifestação para consagrar ou constituir grupos, sejam eles já estabelecidos ou por se estabelecer. Em essência, o poder simbólico está baseado em duas condições. Primeira, na forma performática, em que o poder deve estar concentrado na posse de um capital específico, em outras palavras, ‘... o poder de impor às outras mentes uma visão, antiga ou nova, das divisões sociais depende da autoridade social adquirida nas lutas anteriores. O capital simbólico é um crédito, é o poder atribuído àqueles que obtiveram reconhecimento suficiente para ter condição de impor o reconhecimento.' E segunda, na dependência do grau em que essa visão estiver alicerçada na realidade” (MARCHI JR., 2001, p. 52)
} 
No futsal, a mudança de regras paulatinamente proposta pela FIFA alterou de forma considerável a jogabilidade. Se a outra forma de jogar previa laterais com as mãos, no padrão de regras da FIFA atual o lateral é cobrado com os pés, o que torna a reposição mais rápida e o jogo mais dinâmico. O goleiro, que era restrito à área de defesa, agora pode subir ao campo de ataque, mudando consideravelmente a possibilidade de um jogo de cinco jogadores na linha contra quatro adversários, o que costuma ser chamado de goleiro-linha. Esse elemento permitiu a adição de uma carga emocional diferente nos jogos mais disputados, pois, ao mesmo tempo em que há uma superioridade numérica do time que busca igualar o placar, há o risco de se jogar sem goleiro e tomar um gol de contra-ataque. $\mathrm{O}$ uso da área pelos jogadores também se alterou, visto que a outra forma de jogar previa que apenas o goleiro poderia usar a área. Com as mudanças na regra, existem lances dentro da área que são realizados de forma mais plástica, o que rende grande popularidade ao futsal.

Assim, as transformações nas regras do jogo acabaram por selecionar técnicas corporais diferentes das anteriores e mudaram, de certa forma, as técnicas e as táticas exigidas no jogo. Fica claro que, da mesma forma como ocorreu no voleibol, as mudanças no futsal serviram aos intentos televisivos e de divulgação do esporte. Isso pode ser constatado na distinta visibilidade existente entre o futsal jogado nas regras da FIFA, amplamente conhecido no Brasil, e as práticas realizadas de acordo com as regras da Associação Mundial de Futsal $(\mathrm{AMF})$, pouco conhecidas mesmo em território brasileiro.

\section{Considerações finais}

Após uma longa discussão sobre o futsal, suas histórias, permanências e rupturas, voltamos à pergunta apresentada por Marc Bloch (2001): enfim, para que serve a história? Mais especificamente, para que serve contar a história de um esporte como o futsal?

Decididamente, as respostas a essa pergunta são muitas e não seria possível elencá-las todas aqui. No entanto, podem-se listar breves apontamentos sobre o que pode ser repensado ao se fazer história, especialmente a dos esportes.

Pensar na origem de determinado esporte, nas federações que o comandaram e nas mudanças das regras não é útil apenas para realizar um histórico da modalidade. Tampouco, para figurar numa linha do tempo, ou ainda nos álbuns de figurinhas e programas de televisão. As discussões levantadas neste artigo nos ajudam a perceber que, mais do que construir um histórico sobre determinada modalidade, é preciso pensar, como destacou Bourdieu (2003, p. 181), em "como foi possível que...". Assim, como foram possíveis tantas transformações nas regras do futsal? Como foi possível que o Brasil tenha se tornado uma grande potência desse esporte? Como foi possível que o futsal tenha se tornado um dos esportes mais praticados no país? Como foi possível que o futsal fizesse parte da grade televisiva brasileira, tão pouco aberta a práticas que não sejam o futebol de campo masculino?

No âmbito deste artigo, não foram oferecidas respostas a essas perguntas, mas sim possibilidades de interpretação. Pensar na origem do futebol de salão como um dado histórico e nas transformações do jogo como elementos que têm significado social é pensar no futsal como um elemento da cultura brasileira. Nesse sentido, a prática e a ressignificação desta prática ocorrem a todo momento na sociedade. Assim, este artigo tentou esboçar alguns outros pontos de partida para se pensar a história do futsal e suas inúmeras relações com a sociedade brasileira. 


\section{Referências}

BLOCH, M. L. B. Apologia da história, ou, $O$ ofício de historiador. Rio de Janeiro: Zahar, 2001.

BOURDIEU, P. Algumas propriedades dos campos. In: Questões de sociologia. Lisboa: Fim de século, 2003. 2003. Como é possível ser esportivo? In: Questões de sociologia. Lisboa: Fim de século,

BREITKREITZ, L. A. A ditadura e o futebol na América do Sul: a construção de um imaginário coletivo através das copas do mundo de 1970 e 1978. SEMINA - Revista de PósGraduandos em História, v. 11, n. 1, p. 1-13, 2012.

CHARTIER, R. A história cultural: entre práticas e representações. Rio de Janeiro: Editora Bertrand Brasil, 1990.

DAOLIO, J. Cultura: educação física e futebol. Campinas: Editora da Unicamp, 2006.

DAMATTA, R. et al. O universo do futebol: esporte e sociedade brasileira. Rio de Janeiro: Pinakotheke, 1982.

DRUMOND, M. Nações em jogo: esporte e propaganda política em Vargas e Perón. Rio de Janeiro: Apicuri, 2008.

ESTA COPA É NOSSA. Revista Placar. Editora Abril, 28 maio 1982, p. 32.

ESTE CANECO JÁ É NOSSO. Revista Placar. Editora Abril, 11 jun.1982, p. 10.

GIGLIO, S. S. Futebol: mitos, ídolos e heróis. 2007. 160 f. Dissertação (Mestrado) Universidade Estadual de Campinas, Faculdade de Educação Física, Campinas, SP, 2007.

GUTTMANN, A. From ritual to record. New York: Columbia University Press, 2004.

O ESPORTE da bola pesada que virou uma paixão. [S. 1.], 2015. Disponível em:

<http://www.cbfs.com.br/2015/futsal/origem/index.html>. Acesso em: 7 out. 2017.

MARCHI JUNIOR, W. "Sacando" o voleibol: do amadorismo à espetacularização da modalidade no Brasil (1970-2000). 2001. 267 f. Tese (Doutorado) - Universidade Estadual de Campinas, Faculdade de Educação Física, Campinas, SP, 2001.

MASCARENHAS, F. Entre o ócio e o negócio: teses acerca da anatomia do lazer. 2005. 308 f. Tese (Doutorado) - Universidade Estadual de Campinas, Faculdade de Educação Física, Campinas, SP, 2005.

MELO, V. A. Cidade Sportiva: o turfe e o remo no Rio de Janeiro (1849-1903). Motus Corporis (UGF), Rio de Janeiro, v. 7, n. 1, p. 191-199, 2000. 
Entre a elite e o povo: o sport no Rio de Janeiro do século XIX (1851-1857). Tempo, Niterói, v. 21, n. 37, p. 208-229, 2015.

2015 .

O sport em transição: Rio de Janeiro, 1851-1866. Movimento, v. 21, p. 363-376,

Evidência e especulação: “a origem” do futebol no Rio de Janeiro (18981902). Movimento, v. 23, p. 819-934, set. 2017.

NESSA COPA SÓ DÁ BRASIL. Revista Placar. Editora Abril, 4 jun. 1982, p. 84.

SANTOS, R. P. dos. Futebol e História: uma jogada da modernidade? Uma história comparada entre o desenvolvimento do futebol no Rio de Janeiro e em Buenos Aires (18971924). 2006. 170f. Dissertação (Mestrado) - Programa de Pós-Graduação em História Comparada, Instituto de Filosofia e Ciências Sociais, UFRJ, Rio de Janeiro, 2006.

VEYNE, P. Como se escreve a história. Lisboa: Edições 70, 2008.

VICARI, P. R. Futebol de Salão no Rio Grande do Sul: apontamentos históricos sobre o esporte. 2014. 51f. Trabalho de Conclusão de Curso (Graduação em Bacharelado em Educação Física) - Universidade Federal do Rio Grande do Sul, Porto Alegre, 2014.

VIGARELLO, G. Du jeu ancien au show sportif: la naissance d'une mythe. Paris: Editions du Seuil, 2002.

ZARATIM, S. R. Aspectos socioculturais do futsal. Revista Eletrônica de Educação da Faculdade Araguaia - RENEFARA, v. 2, p. 51-62, 2012.

Recebido em: 07/02/2018

Revisado em: 29/03/2018

Aprovado em: 04/06/2018

Endereço para correspondência:

danieli_ccm@hotmail.com

Daniele Cristina Carqueijeiro de Medeiros

Universidade Estadual de Campinas, Campinas, São Paulo, Brasil.

Faculdade de Educação - Unicamp

Av. Bertrand Russell, 801

Cidade Universitária "Zeferino Vaz"

13083-865 Campinas - SP, Brasil 